\title{
Chemical composition and insecticidal activity of essential oil from Ziziphora clinopodioides Lam. used against the Mediterranean flour moth, Ephestia kuehniella Zeller
}

\author{
Mohammad Kheirkhah*, Vahid Ghasemi, Asghar Khoshnood Yazdi, Samaneh Rahban
}

Department of Plant Production Technology, Faculty of Agriculture, Higher Education Complex of Shirvan, Northern Khorasan, 9468194477, Iran

Received: May 4, 2015

Accepted: June 17, 2015

\begin{abstract}
The Mediterranean flour moth, Ephestia kuehniella Zeller, is a major pest of stored grain products, particularly flour. There have been major concerns over the application of conventional insecticides in stored products, which have strongly demonstrated the need for applying such alternative safe compounds as essential oils. The aim of the present study is to investigate the chemical composition and fumigant toxicity of essential oil from Ziziphora clinopodioides Lam. against the eggs, larvae, and adults of E. kuehniella. All toxicity tests were carried out under laboratory conditions set at $26 \pm 1^{\circ} \mathrm{C}$ and $70 \%$ relative humidity (RH). The results of gas chromatography-mass spectrometry (GC/MS) analysis indicated that the essential oil extracted from the leaves of Z. clinopodioides, is rich in pulegone $(49.4 \%)$, piperitenone $(10.7 \%)$, menthone $(8.9 \%)$, and 1,8-cineol $(6.9 \%)$. Based on the bioassay results, the LC $_{50}$ value of the tested oil was estimated to be $54.61 \mu \mathrm{l} \cdot \mathrm{l}^{-1}$ air for larvae and $1.39 \mu \mathrm{l} \cdot \mathrm{1}^{-1}$ air for adults. Also, it is shown that increasing the oil concentration resulted in a significant increase in oviposition deterrency as well as a considerable reduction in the egg hatching percentage. These results suggest that Z. clinopodioides oil could be a potential candidate as a fumigant for managing E. kuehniella in stored products.
\end{abstract}

Key words: Ephestia kuehniella, Ziziphora clinopodioides, chemical composition, fumigant toxicity, oviposition deterrency, egg hatching

\section{Introduction}

The pyralid Mediterranean flour moth, Ephestia kuehniella Zeller, is distributed world-wide. This moth is a serious pest of stored grain products as well as flour and other milled products (Khebbeb et al. 2008). Many storage systems rely on the use of synthetic insecticides and fumigants like methyl bromide $(\mathrm{MeBr})$ and phosphine (PH3) to control stored-product pests. These synthetic insecticides and fumigants are the most economical and convenient tools for managing these pests (Mueller 1990). Despite their satisfying results, the use of chemical fumigants is being restricted in many countries because of the fumigants' dangerous side effects such as contamination of stored products, the ecological consequences (Butler and Rodriguez 1996; MBTOC 1998), and an increased probability of insect resistance (Meaklim 1998; Haque et al. 2000). These problems have highlighted the need for developing new safe kinds of selective insect-control alternatives with fumigant action.

Plant materials, especially essential oils, have received special attention as alternative compounds to the currently used insecricides. The ability of the oils to control stored-product pests due to the low mammalian toxicity and sound environmental profile of the oils, is drawing a lot of attention to them (Isman 2000). In recent years, several experiments have been conducted to assess the efficacy of essential oils against stored-product insect species (Kim et al. 2013; Ziaee et al. 2014; Kim and Lee 2014; Nwachukwu and Asawalam 2014; Fatiha et al. 2014; Aref et al. 2015). For example, Karaborku et al. (2011) indicated that Marjoram (Origanum majorana L.) and Lemon (Citrus limon L.) oils were very effective against E. kuehniella. Also, Ghasemi et al. (2013) showed the fumigant toxicity of essential oils from Callistemon viminalis Gaertn. and Ferula gummosa L. on larvae of E. kuehniella.

Lamiaceae is a large plant family with many important species. In this family, Ziziphora clinopodioides Lam. with the Persian name "kakuti-e-kuhi", is a plant widely used in Iranian traditional medicine because of its antibacterial (Salehi et al. 2005; Sonboli et al. 2006; Murat and Pinar 2009), antifungal (Behravan et al. 2007), antioxidant (Meral et al. 2002; Salehi et al. 2005), and anti-inflammatory (Ghafari et al. 2006) properties. Also, the essential oil from Z. clinopodioides has been proved to possess insecticidal activity agains adults and eggs of one of the most destructive pests of stored products, Callosobruchus maculatus Fab. (Lolestani and Shayesteh 2009). Nevertheless, there has not yet been any report on the insecticidal activity of Z. clinopodioides oil against E. kuehniella.

We evaluated the chemical composition of the essential oil from $Z$. clinopodioides and the efficiency of the oil 
as a possible fumigant in the management of the Mediterranean flour moth.

\section{Materials and Methods}

\section{Culturing insects}

Eggs of E. kuehniella were provided by the Insectarium of Scientific and Industrial Research Organization of Iran. Three hundred of one-day-old eggs were reared in one plastic container $(25 \mathrm{~cm}$ length, $15 \mathrm{~cm}$ width, and $10 \mathrm{~cm}$ height) half filled with a mixture of equal amounts of wheat flour and bran. Powdered yeast $(5 \mathrm{~g})$ was also added to each jar. The rearing conditions were $26 \pm 1^{\circ} \mathrm{C}$ and $75 \%$ relative humidity $(\mathrm{RH})$ in darkness.

\section{Plant materials}

Aerial parts of Z. clinopodioides were collected from their natural habitats in Iran. The plant material was dried naturally at room temperature $\left(23-25^{\circ} \mathrm{C}\right)$ for 5 days until crisp. The dried material was stored at $24^{\circ} \mathrm{C}$ until required.

\section{Extraction and chemical analysis of the essential oil}

Essential oil was extracted from the plant sample using a modified Clevenger-type apparatus (Negahban et al. 2007). The conditions of extraction were: $40 \mathrm{~g}$ of air-dried sample, $500 \mathrm{ml}$ distilled water, and $3 \mathrm{~h}$ distillation. After extraction, anhydrous sodium sulfate was used to eliminate water. The extracted oil was placed in a sealed glass tubes and stored at $4^{\circ} \mathrm{C}$ for chemical analysis and bioassay tests.

Gas chromatographic (GC) analysis was performed using a Thermoquest-finnigan on a DB-1 fused-silica capillary column $(60 \mathrm{~m} \times 0.25 \mathrm{~mm}$ i.d., $0.25 \mu \mathrm{m}$ film thickness). The temperature was programmed to rise to a $60^{\circ} \mathrm{C}$ and then to $250^{\circ} \mathrm{C}$ at $5^{\circ} \mathrm{C} \cdot \mathrm{min}^{-1}$. Injector and detector temperatures were 250 and $280^{\circ} \mathrm{C}$, respectively. The detector was a flame ionisation detector (FID) and nitrogen was used as a carrier gas at a flow rate of $1.1 \mathrm{ml} \cdot \mathrm{min}^{-1}$. Gas chromatography-mass spectrometry (GC/MS) was carried out using a Thermoquest-finnigan with the same characteristics as the one used in GC. The mass detector was Thermo-finnigan quadruple. Helium was used as a carrier gas at $1.1 \mathrm{ml} \cdot \mathrm{min}^{-1}$. The ionisation energy was $70 \mathrm{eV}$ with a mass range of 35-465 amu.

The chemical constituents were identified by comparing their relative retention indices and mass spectra, with those published in the literature (Asawalam et al. 2006), and supplemented with NIST 1.7 and Wiley 7 GC/MS libraries. The relative proportion of the essential oil constituent was computed in each case from the GC/MS peak areas.

\section{Fumigant toxicity bioassays}

To determine the fumigant toxicity of $Z$. clinopodioides oil, 10 of two-day-old 5th instar E. kuehniella larvae were placed in one glass container of $280 \mathrm{ml}$ volume. After preliminary dose-setting experiments, the final concentrations of the oil causing 5-95\% mortality were obtained based on logarithmic distance (Robertson et al. 2007). The calculated concentrations of the oil were infused on the filter paper (Whatman No. 1, cut into $2 \mathrm{~cm}$ diameter pieces) and then were attached to the caps of the glass vials. Oils were applied as pure oils, and were applied using a microapplicator. The caps of the vials were sealed tightly with Parafilm. The control larvae received no oil. The same experiment was designed to assess the fumigant toxicity of the tested oil against adult (0-24 h old) E. kuehniella insects.

In both assays, all treatments and controls were kept at $26 \pm 1^{\circ} \mathrm{C}$ and $70 \% \mathrm{RH}$ in darkness. Each concentration and control was replicated three times. Mortality was determined after $24 \mathrm{~h}$ from the start of exposure. When no leg or antennal movements were observed, insects were considered dead. The percentage of insect mortality was calculated using the Abbott correction formula for natural mortality in the untreated controls (Abbott 1925).

\section{Oviposition deterrence and egg hatching}

In this experiment, two pairs ( 2 males and 2 females) of adult moths were selected for each concentration and for the control. Glass vials $(250 \mathrm{ml})$, containing $5 \mathrm{~g}$ of mung bean grains, were treated with $1 \mathrm{ml}$ concentrations of 500; 1,$000 ; 2,000 ; 4,000$, and 8,000 ppm Z. clinopodioides oil, as uniformly as possible. In the control, the food was treated only with a solvent (acetone). After evaporation of the acetone ( 20 $\mathrm{min}$ ), newly emerged E. kuehniella adults were transferred to the vials. Three replications were used for each concentration. The number of laid eggs per female was recorded after $96 \mathrm{~h}$. Oviposition deterrence was calculated with the following formula (Pascual-Villalobos and Robledo 1998):

$$
\% \text { Oviposition deterrence }=\left[1-\frac{N E_{t}}{N E_{c}}\right] \times 100,
$$

where $N E_{t}$ - the number of eggs in a treatment, and $N E_{c}-$ the number of eggs in the control.

Also, twenty eggs were selected from each replication and the effect of the essential oil on the egg hatching was recorded until all of the eggs in the control were hatched.

\section{Statistical analysis}

The LC values and 95\% confidence limits were calculated from probit regressions using the POLO-PC computer program (LeOra Software). Data from oviposition deterrence and egg hatching assays were analysed using the SPSS programe version 16.0 for analysis of variance (ANOVA). Data obtained in percentages was subjected to the Arcsine $\sqrt{\frac{x}{100}}$ before ANOVA. The means were grouped using Tukey's test $(\alpha=0.05)$.

\section{Results}

\section{Chemical constituents of Ziziphora clinopodioides oil}

The yield of the essential oil from $Z$. clinopodioides was $2.3-2.5 \%$ (v/w based on dry weight). A total of 34 components from the essential oil of $Z$. clinopodioides were 
identified, accounting for $94.48 \%$ of the total oil (Table 1). The major constituent in the oil was pulegone $(49.4 \%)$, followed by piperitenone $(10.7 \%)$, menthone $(8.9 \%)$ and 1,8 -cineol $(6.9 \%)$, iso-menthone $(3.9 \%)$, iso-pulegone $(2.9 \%)$, and limonene $(2.8 \%)$.

\section{Toxicity tests}

Data from the fumigant toxicity of Z. clinopodioides oil on E. kuehniella larvae and adults are presented in table 2. As is shown, $\mathrm{LC}_{50}$ of tested oil was determined to be $54.61 \mu \mathrm{l}$. $\cdot \mathrm{l}^{-1}$ air for larvae and $1.39 \mu \mathrm{l} \cdot \mathrm{l}^{-1}$ air for adults. According to $\mathrm{LC}_{50}$ values and estimated relative median potency (RMP), the adults were 42.17 times more sensitive than the larvae to Z. clinopodioides oil (Table 2).

\section{Oviposition deterrence and egg hatching}

The different concentrations of the Z. clinopodioides oil's oviposition deterrence activity on the females of E. kuehniella are shown in table 3 . The results indicated that the number of eggs laid by the females decreased as concentrations of the oil were increased from 500 to $8,000 \mathrm{ppm}$. On the other hand, the oil's oviposition deterrency significantly increased with increased concentrations of the oil $(F=295.26 ; d f=5 ; p=0.000)$. As is shown, treating female moths with concentrations of 2,000;4,000, and 8,000 ppm of the oil caused a 51.11, 72.02, and $89.89 \%$ decline in the oviposition rate, respectively. Also, increasing the essential oil concentration resulted in a significant decrease in the egg hatching percentage $(\mathrm{F}=21.29 ; \mathrm{df}=5 ; \mathrm{p}=0.000)$ (Table 3).

Table 1. Chemical constituents of the essential oil from Ziziphora clinopodioides

\begin{tabular}{|c|c|c|}
\hline Compound & Retention index & $\%$ Composition \\
\hline$\alpha$-thujene & 928 & 0.08 \\
\hline$\alpha$-pinene & 937 & 1.2 \\
\hline 3-methylcyclohexanone & 950 & 0.1 \\
\hline camphene & 954 & 0.1 \\
\hline 1-octen-3-ol & 973 & 0.1 \\
\hline sabinene & 976 & 1.0 \\
\hline$\beta$-pinene & 983 & 1.5 \\
\hline$\beta$-myrcene & 988 & 0.4 \\
\hline 3-octanol & 990 & 0.3 \\
\hline p-mentha-1(7)-dine & 1008 & 0.1 \\
\hline p-cymene & 1027 & 0.2 \\
\hline limonene & 1033 & 2.8 \\
\hline 1,8-cineol & 1037 & 6.9 \\
\hline 3-ethyl-2-hydroxy-2-cyclopenten-1-one & 1053 & 0.1 \\
\hline trans-sabinene hydrate & 1071 & 0.1 \\
\hline linalool & 1100 & 0.1 \\
\hline 3-octanol acetate & 1119 & 0.1 \\
\hline cis-p-mentha-2,8-dien-1-ol & 1142 & 0.1 \\
\hline menthone & 1162 & 8.9 \\
\hline iso-menthone & 1172 & 3.9 \\
\hline iso-pulegone & 1181 & 2.9 \\
\hline 2-(2-methylallyl) 2-cyclohexene-1-one & 1217 & 0.2 \\
\hline coahuiolensol methyl ether & 1234 & 0.4 \\
\hline pulegone & 1258 & 49.4 \\
\hline piperitone & 1265 & 1.9 \\
\hline iso-piperitenone & 1279 & 0.2 \\
\hline lavandulyl acetate & 1300 & 0.2 \\
\hline piperitenone & 1353 & 10.7 \\
\hline piperitenone oxide & 1372 & 0.1 \\
\hline$\alpha$-copaene & 1390 & 0.1 \\
\hline$\beta$-boubonene & 1401 & 0.1 \\
\hline trans-geranyl acetone & 1451 & 0.1 \\
\hline trans- $\beta$-lonone & 1492 & 0.1 \\
\hline spathulenol & 1596 & 0.1 \\
\hline Total identified & & 94.48 \\
\hline
\end{tabular}

Bold values indicate the most abundant constituents of the oil 
Table 2. Fumigant toxicity of Ziziphora clinopodioides oil against Ephestia kuehniella

\begin{tabular}{lccccc}
\hline \multicolumn{1}{c}{ Stage } & $\mathrm{n}$ & $\begin{array}{c}\mathrm{LC}_{50} \text { values } \\
\left(\mu \mathrm{l} \cdot \mathrm{l}^{-1} \text { air }\right)^{\mathrm{a}}\end{array}$ & Slope \pm SE & $\chi^{2}(\mathrm{df})$ & $\mathrm{RMP}_{(95 \% \mathrm{CL})^{\mathrm{b}}}$ \\
\hline Larvae & 240 & $54.61(35.07-83.47)$ & $1.03 \pm 0.14$ & $1.02(5)$ & $42.17(5.99-85.71)$ \\
Adults & 210 & $1.39(1.15-1.66)$ & $2.70 \pm 0.37$ & - & - \\
\hline
\end{tabular}

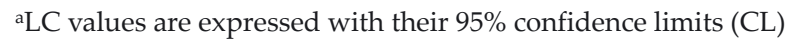

belative Median Potency $=\mathrm{LC}_{50}$ of larvae divided by $\mathrm{LC}_{50}$ of adults

Table 3. Effect of Ziziphora clinopodioides oil on oviposition rate, percentage oviposition deterrence, and egg hatching of Ephestia kuehniella, after $96 \mathrm{~h}$ fumigation (the mean $\pm \mathrm{SE}$ )

\begin{tabular}{cccc}
\hline Concentration [ppm] & $\begin{array}{c}\text { Oviposition [number of eggs laid } \\
\text { per female] }\end{array}$ & Oviposition deterrence [\%] & Egg hatching [\%] \\
\hline 0 & $330.33 \pm 17.53 \mathrm{f}$ & $0 \mathrm{f}$ & $95.12 \pm 2.88 \mathrm{c}$ \\
500 & $296.00 \pm 7.57 \mathrm{e}$ & $10.30 \pm 2.29 \mathrm{e}$ & $90.05 \pm 5.02 \mathrm{c}$ \\
1,000 & $236.00 \pm 9.84 \mathrm{~d}$ & $28.48 \pm 2.98 \mathrm{~d}$ & $81.66 \pm 4.40 \mathrm{bc}$ \\
2,000 & $161.33 \pm 8.21 \mathrm{c}$ & $51.11 \pm 2.48 \mathrm{c}$ & $60.42 \pm 5.77 \mathrm{ab}$ \\
4,000 & $92.33 \pm 4.66 \mathrm{~b}$ & $72.02 \pm 1.41 \mathrm{~b}$ & $35.12 \pm 2.88 \mathrm{a}$ \\
8,000 & $33.33 \pm 5.36 \mathrm{a}$ & $89.89 \pm 1.62 \mathrm{a}$ & $25.21 \pm 2.88 \mathrm{a}$ \\
\hline
\end{tabular}

Means followed by the different letters in each column indicate significant differences at $\mathrm{p}<0.05$, Tukey's test

\section{Discussion}

In the present study, we evaluated the insecticidal activity of the essential oil from Z. clinopodioides on the larvae and adults of the important E. kuehniella, stored-product pests. Our results demonstrated the fumigant toxicity of Z. clinopodioides oil to the studied stages of E. kuehniella, but the insecticidal activity varied with the developmental stages. Also, the tested oil showed outstanding oviposition deterrence and ovicidal activity agaist E. kuehniella.

Many essential oils extracted from different plant spices have already been screened for toxicity as potential insecticide agains E. kuehniella. The essential oil of Satureja hortensis L. showed fumigant toxicity against larvae of E. kuehniella (Maedeh et al. 2011). Essential oil derived from Pistacia lentiscus L. is known to have toxic effects on E. kuehniella (Bachrouch et al. 2010). The essential oil from oregano, Origanum onites L., and savory, Satureja thymbra L. has also been reported to have fumigant toxicity toward adults of E. kuehniella (Ayvaz et al. 2010). However, no report is available concerning the insecticidal property of $Z$. clinopodioides oil as a fumigant.

Essential oils are generally broad spectrum due to the presence of several active ingredients that may operate through various modes of action (Chiasson et al. 2004). The insecticidal activity of plant essential oils is reported to be mainly due to their content of monoterpenoids (Obeng-Ofori and Reichmuth 1999; Huang et al. 2002; Lee et al. 2002, 2003) with an indication of a neurotoxic mode of action (Isman et al. 2007), which is mainly due to inhibition of acetylcholinesterase activity (Abdelgaleil et al. 2009; Yeom et al. 2012). Pulegone, piperitenone, menthone, and 1,8-cineol are shown to be the main constituents of
Z. clinopodioides oil which is in agreement with those reported by Ghafari et al. (2006), Sonboli et al. (2006), and Amiri (2009). Pulegone is about $50 \%$ of the total Z. clinopodioides oil and is the most powerful of the three insecticides naturally occurring in many mint species (Franzios et al. 1997). These volatile compounds, are more useful as insect fumigants against stored-product pests Numerous reports note the insecticidal activity of plant essential oils containing these chemical components against different species of pests (Ghasemi 2010, 2013; Hamzavi 2011).

In the present study, we observed that E. kuehniella adults (0-24 h old) were less tolerant than larvae (twoday-old fifth instar) to the oil. Similar results have been reported by Khodadoust and Moharramipour (2010), who showed that E. kuehniella adults were more susceptible than larvae instars to (Cuminum cyminum L.) and ( $\mathrm{Ca}$ rum copticum C.B. Clarke) essential oils. In another experiment, Emamjomeh et al. (2014) indicated that essential oil of Zataria multiflora Boiss. was more toxic to E. kuehniella adults than to the larvae.

\section{Conclusion}

The essential oil investigated in this study is used as a pharmaceutical and in flavouring and is therefore considered less harmful to humans and non-target organisms than most conventional pesticides. It was shown that the essential oil from Z $Z$. clinopodioides was toxic to the eggs, larvae, and adults of E. kuehniella when applied as a fumigant in laboratory conditions. However, further semifield and field evaluations are needed to confirm that this essential oil can be used as an effective safe insecticide in storage systems. 


\section{References}

Abbott W.S. 1925. A method of computing the effectiveness of an insecticide. Journal of Economic Entomology 18: 265-267.

Abdelgaleil S.A.M., Mohamed M.I.E., Badawy M.E.J., El-arami S.A.A. 2009. Fumigant and contact toxicities of monoterpenes to Sitophilus oryzae (L.) and Tribolium castaneum (Herbst) and their inhibitory effects on acetylcholinesterase activity. Journal of Chemical Ecology 35: 518-525.

Amiri H. 2009. Composition and antioxidant activity of the essential oil and methanolic extract of Ziziphora clinopodioides Lam. in pre-flowering stage. Journal of Kerman University of Medical Sciences 16 (1): 79-86.

Aref S.P., Valizadegan O., Farashiani M.E. 2015. Eucalyptus dundasii Maiden essential oil, chemical composition and insecticidal values against Rhyzopertha dominica (F.) and Oryzaephilus surinamensis (L.). Journal of Plant Protection Research 55 (1): 35-41.

Asawalam E.F., Emosairue S.O., Hassanali A. 2006. Bioactivity of Xylopia aetiopia (Dunal) A. Rich essential oil constituents on maize weevil Sitophilus zeamais Motschulsky (Coleoptera: Curculionidae). Electronic Journal of Environmental, Agricultural and Food Chemistry 5 (1): 1195-1204.

Ayvaz A., Sagdic O., Karaborklu S., Ozturk I. 2010. Insecticidal activity of the essential oils from different plants against three stored-product insects. Journal of Insect Science 10 (1): 21-26.

Bachrouch O., Mediouni-Ben Jemâa J., Wissem A.W., Talou T., Marzouk B., Abderraba M. 2010. Composition and insecticidal activity of essential oil from Pistacia lentiscus L. against Ectomyelois ceratoniae Zeller and Ephestia kuehniella Zeller (Lepidoptera: Pyralidae). Journal of Stored Product Research 46 (4): 242-247.

Behravan J., Ramezani M., Hassanzadeh M.K., Eskandari M., Kasaian J., Sabeti Z. 2007. Composition, antimycotic and antibacterial activity of Ziziphora clinopodioides Lam. essential oil from Iran. Journal of Essential Oil-Bearing Plants 10 (4): 339-345.

Butler J.H., Rodriguez J.M. 1996. Methyl bromide in the atmosphere. p. 27-90. In: "The Methyl Bromide Issue". Vol. 1. (C.H. Bell, N. Price, B. Chakrabarti, eds.). Wiley, West Sussex, England, 412 pp.

Chiasson H., Vincent C., Bostanian N.J. 2004. Insecticidal properties of a Chenopodium-based botanical. Journal of Economic Entomology 97 (4): 1378-1383.

Emamjomeh L., Imani S., Talebi K., Moharramipour S., Larijani K. 2014. Chemical composition and insecticidal activity of essential oil of Zataria multiflora Boiss. (Lamiaceae) against Ephestia kuehniella (Lepidoptera: Pyralidae). European Journal of Experimental Biology 4 (3): 253-257.

Fatiha R.A., Kadal R., Khelil M.A., Pujade-Villar J. 2014. Biological control against the cowpea weevil (Callosobruchus chinensis L., Coleoptera: Bruchidae) using essential oils of some medicinal plants. Journal of Plant Protection Research 54 (3): 211-217.

Franzios G., Mirotsou M., Hatziapostolou E., Kral J., Scouras Z.G., Mavragani-Tsipidou P. 1997. Insecticidal and genotoxic activities of mint essential oils. Journal of Agricultural and Food Chemistry 45 (7): 2690-2694.

Ghafari H., Yasa N., Mohamadirad A., Dehghan G. 2006. Protection by Ziziphora clinopodioides of acid-induced toxic bowel inflammation through reduction of cellular lipid peroxidation and myeloperoxidase activity. Human Experimental Toxicology 6: 325-332.

Ghasemi V. 2010. Fumigant toxicity of four plant essential oils on Varroa destructor and Apis mellifera. M.Sc. thesis, Faculty of Agriculture, Department of Agricultural Entomology, Tarbiat Modares University, 113 pp.

Ghasemi V., Khoshnood Yazdi A., Zaker Tavallaie F., Jalali Sendi J. 2014. Effect of essential oils from Callistemon viminalis and Ferula gummosa on toxicity and on the hemocyte profile of Ephestia kuehniella (Lep.: Pyralidae). Archives of Phytopathology and Plant Protection 47 (3): 268-278.

Hamzavi F. 2011. Insecticidal effects of essential oil from Eucalyptus camaldulensis Dehnh and Bottlebrush Callistemon viminalis Gaertn. on three species of stored-product bettles. M.Sc. thesis, Faculty of Agriculture, Department of Agricultural Entomology, Tarbiat Modares University, 134 pp.

Haque M.A., Nakakita H., Ikenaga H., Sota N. 2000. Development inhibiting activity of some tropical plants against $\mathrm{Si}$ tophilus zeamais Motschulsky (Coleoptera: Curculionidae). Journal of Stored Product Research 36: 281-287.

Huang Y., Ho S., Lee H., Yap Y. 2002. Insecticidal properties of eugenol, isoeugenol and methyleugenol and their effects on nutrition of Sitophilus zeamais Motsch. (Coleoptera: Curculionidae) and Tribolium castaneum (Herbst) (Coleoptera: Tenebrionidae). Journal of Stored Product Research 38 (5): 403-412.

Isman M.B. 2000. Plant essential oils for pest and disease management. Crop Protection 19 (8-10): 603-608.

Isman M.B., Machial C., Miresmailli S., Bainard L. 2007. Essential oil-based pesticides: new insights from old chemistry. p. 201-209. In: "Pesticide Chemistry" (H. Ohkawa, H. Miyagawa, P. Lee, eds.). Wiley-VCH, Weinheim, Germany, $497 \mathrm{pp}$.

Karaborku S., Ayvaz A., Yilmaz S., Akbulut M. 2011. Chemical composition and fumigant toxicity of some essential oils against Ephestia kuehniella. Journal of Economic Entomology 104 (4): 1212-1219.

Khebbeb M.E.H., Gaouaoui R., Bendjeddou F. 2008. Tebufenozide effects on the reproductive potentials of the Mediterranean flour moth, Ephestia kuehniella. African Journal of Biotechnology 7 (8): 1166-1170.

Khodadoust M., Moharramipour S. 2010. Insecticidal effects of essential oil of Cuminum cyminum L. and Carum copticum C.B. Clarke on Ephestia kuehniella Zeller. Proceedings of the 19th Iranian Plant Protection Congress, Iranian Research Institute of Plant Protection, Tehran, Iran, 31 July-3 August 2010, 205 pp.

Kim S.W., Kang J., Park I.K. 2013. Fumigant toxicity of Apiaceae essential oils and their constituents against Sitophilus oryzae and their acetylcholinesterase inhibitory activity. Journal of Asia-Pacific Entomology 16 (4): 443-448.

Kim S.I., Lee D.W. 2014. Toxicity of basil and orange essential oils and their components against two coleopteran stored products insect pests. Journal of Asia-Pacific Entomology 17 (1): 13-17.

Lee B.H., Lee S.E., Annis P.C., Pratt S.J., Park B.S., Tumaalii F. 2002. Fumigant toxicity of essential oils and monoterpenes against the red flour beetle, Tribolium castaneum Herbst. Journal of Asia-Pacific Entomology 5 (2): 237-240. 
Lee S., Peterson C.J., Coats J.R. 2003. Fumigation toxicity of monoterpenoids to several stored product insects. Journal of Stored Product Research 39 (1): 77-85.

Lolestani F.A., Shayesteh N. 2009. Fumigant toxicity of Ziziphora clinopodioides (Lamiaceae) against adults and eggs of Callosobruchus maculatus (Fab.) (Coleoptera: Bruchidae). Journal of Biological Sciences 9 (1): 92-95.

Maedeh M., Hamzeh I., Hossein D., Majid A., Reza R.K. 2011. Bioactivity of essential oil from Satureja hortensis (Laminaceae) against three stored-product insect species. African Journal of Biotechnology 10 (34): 6620-6627.

MBTOC 1998. Methyl Bromide Technical Options Committee: Assessmentof alternatives to methyl bromide. Nairobi, Kenya, United Nations Environment Programme, Ozone Secretariat, $374 \mathrm{pp}$.

Meaklim J. 1998. Phosphine toxicity: are phosphine users, or the general community, at risk of adverse health effects. p. 119-125. In: "Stored Grain in Australia" (H.J. Banks, E.J. Wright, K.A. Damcevski, eds.). Proceedings of the Australia Postharvest Technical Conference, Canberra, 26-29 May 1998, 275 pp.

Meral G.E., Konyalioglu S., Ozturk B. 2002. Essential oil composition and antioxidant activity of endemic Ziziphora taurica subsp. cleonioides. Fitoterapia 73 (7-8): 716-718.

Mueller D.K. 1990. Fumigation. p. 901-939. In: “Handbook of Pest Control" (A. Mallis, ed.), Franzak and Foster Co., Cleveland, Ohio, USA, 1400 pp.

Murat K., Pinar E. 2009. The antimicrobial activities of methanolic extracts of some Lamiaceae members collected from Turkey. Turkish Journal of Science and Technology 4 (1): 81-85.

Negahban M., Moharramipour S., Sefidkon F. 2007. Fumigant toxicity of essential oil from Artemisia sieberi Besser against three stored-product insects. Journal of Stored Product Research 43 (2): 123-128.
Nwachukwu I.D., Asawalam E.F. 2014. Evaluation of freshly prepared juice from garlic (Allium sativum L.) as a biopesticide against the maize weevil, Sitophilus zeamais (Motsch.) (Coleoptera: Curculionidae). Journal of Plant Protection Research 54 (2): 132-138.

Obeng-Ofori D., Reichmuth C. 1999. Plant oils as potential agents of monoterpenes for protection of stored grains against damage by stored product beetle pests. International Journal of Pest Management 45 (2): 155-159.

Pascual-Villalobos M.J., Robledo A. 1998. Screening for anti-insect activity in Mediterranean plants. Industrial Crops and Products 8 (3): 183-194.

Robertson J.L., Russell R.M., Preisler H.K., Savin N.E. 2007. Bioassays with Arthropods. Boca Raton (FL): CRC Press, Boca Raton, Florida, 224 pp.

Salehi P., Sonboli A., Eftekhar F., Nejad-Ebrahimi S., Yousefzadi M. 2005. Essential oil composition, antibacterial and antioxidant activity of the oil and various extracts of Ziziphora clinopodioides subsp. rigida (BOISS.) RECH. f. from Iran. Biological and Pharmaceutical Bulletin 28 (10): 1892-1896.

Sonboli A., Mirjalili M.H., Hadian J., Ebrahimi S.N., Yousefzadi M. 2006. Antibacterial activity and composition of theessential oil of Ziziphora clinopodioides subsp. bungeana (Juz.) Rech. f. from Iran. Verlag der Zeitschrift für Naturforschung [C] 61: 677-680.

Yeom H., Kang J., Kim G., Park I. 2012. Insecticidal and acetylcholine esterase inhibition activity of Apiaceae plant essential oils and their constituents against adults of German cockroach (Blattella germanica). Journal of Agricultural and Food Chemistry 60 (29): 2703-7194.

Ziaee M., Moharramipour S., Francikowski J. 2014. The synergistic effects of Carum copticum essential oil on diatomaceous earth against Sitophilus granarius and Tribolium confusum. Journal of Asia-Pacific Entomology 17 (4): 817-822. 